\title{
Design Experience in a Laboratory Environment
}

\author{
Nagy N. Bengiamin \\ Electrical Engineering Department \\ University of North Dakota \\ Grand Forks, ND
}

\begin{abstract}
This paper addresses enhancing engineering design education via hands-on and open-ended laboratory experience. Design is considered in its broader context of problem solving attributes. A unique laboratory has been developed, in the Electrical Engineering Department at the University of North Dakota, using industrial equipment for motion control and energy management. A new senior laboratory course is designed to enhance students' creativity, problem solving, design, and hands-on skills. Students are presented with equipment, background material, software, and general ideas and concepts. Student teams then determine the scope of their projects and develop their own plan of work. Sample projects are presented.
\end{abstract}

\section{Introduction}

Analysis and Synthesis (design) have always been emphasized in engineering education. The old school of thought, however, was biased towards basic science and analytical skills. Furthermore, design in education was approached from its narrow sense of being discipline oriented. This approach seemed to work well in the past when the technological base was limited. Engineers and scientists were actually blending together without much differentiation, and design on the job used to cross discipline boundaries to produce new technologies, The technology revolution and its fast pace brought a new dimension to engineering education, New engineering technology programs at educational institutions are culminating the notion of the increasing dependence between engineering and technology. Today's engineer must be technology literate. Design is one of the primary vehicles for bringing technologies closer to engineering education. The present school of thought puts design at the heart of engineering education and it broadens its scope to include skills which tie knowledge, behavior, and intellectual abilities. Engineering fundamentals and theoretical and analytical concepts seem to sink in better when linked to applications and engineering design methodologies. The challenge is to emphasize design without compromising basic principles.

"The crux of the design process is in creating a satisfactory solution to a need it is what engineering is all about" [1]. Design is perceived to be "creative problem solving" which requires both creative and critical thinking skills. Conwell, et. al. [1], considered those two skills to be synergistic. The development of one skill aids in the development of the other. Developing these skills requires creative approaches to: (1) Increase student motivation; (2) Improve pedagogy and educational effectiveness; and (3) Better match EE educational content and teaching technology to the needs of the changing EE profession [2]. Crossing discipline boundaries is recognized by many educators for its effectiveness in facilitating creative and critical thinking education [3].

While experimental work and hands-on experiences increase student confidence and reinforce their sense of accomplishment, designing a meaningful laboratory exercise that enhances creative and critical thinking is 
always a challenge. With the support of the National Science foundation (NSF), the Electrical Engineering department at the University of North Dakota designed a new senior laboratory facility. The assembled equipment is unique in its configuration and design to possess desirable features of flexibility, ease of use, ruggedness, broadness, and accessibility to components. These features are important for accomplishing key educational objectives that encourage creativity with a manageable development time.

Using the new facility, students can easily experiment with several sensing devices and design their own experiments to investigate a variety of electromechanical aspects related to energy, controls, and sensory technologies. Typical experiments and design projects will be addressed in this paper to illustrate educational objectives and flexibility in equipment configuration. Challenges in accomplishing the stated educational objectives will also be addressed.

\section{The Senior Laboratory}

Motivated by the need to integrate design throughout the electrical engineering curriculum and to instill in students attributes of creative thinking, the new laboratory was developed. This laboratory takes the place of a traditional electrical machines and energy conversion laboratory. In the previous laboratory, students used to conduct classical experiments to characterize electric machines and transformers. Analog meters and patch panels were the primary way for acquiring data in a well structured weekly experimental environment, The new laboratory differs in many respects including; (1) The scope of the laboratory is broadened to include energy management, energy quality, sensing devices, controls, and automated systems, (2) Interdisciplinary aspects are addressed, (3) Students work in teams on projects which last several weeks each, (4) The students are major contributors to the definition of their own projects, (5) Team work and communication skills are emphasized, (6) Pre-labs and students consultation with each other and with the laboratory instructor take place, and (7) Safety is addressed in a formal way.

The new laboratory is a full semester one-credit course. The students work in groups of three and they are required to work on two major projects and participate in three one-week hands-on/demonstration type experiments. The experiments focus on basic theoretical aspects related to electric machines and energy conversion. The major projects, however, are broader in scope as they include energy conversion, modeling, controls, electric power quality and management, and automation. They extend over five weeks each and they are assigned by a random ballot. In these projects, students are presented with a comprehensive document, about ten pages, which includes a description of one of the available systems, its accessories, safety precautions, and a list of possible experimental tasks. A folder which includes equipment specifications, operating manuals, software listings, and background material is also available. Each group of students is introduced to the actual system and instructed on a safe operating procedure. Students are then required to study the given material and determine the scope of their project. They are encouraged to apply knowledge gained in previous subjects and expand beyond classical electrical engineering issues. They are expected to use knowledge from electric machines, control systems, computer programing, electronics, robotics, and computer simulation to mention a few. A project report and an oral presentationldemonstration are required to disseminate the results of the project.

\section{Equipment}

The available equipment is configured in four main experimental stations, namely, an engine-generator, an industrial robot arm, an adjustable speed drive, and a dc machine servo system. Each station is equipped with an IBM-PC, computer/machine interface, and a working computer control and data acquisition software, In addition to the basic equipment, there are several accessory pieces which can be integrated and used with the basic 
equipment. The purpose of the accessory equipment is to permit flexibility and creativity in conducting experimental work. We expect the inventory of the accessory equipment to grow with the use of the laboratory and the interest of the students. A brief description of the equipment is given below. A complete list and detailed configuration of the equipment can be found in two previous manuscripts by the author [4,5]. Educational objectives were also discussed in these manuscripts. For immediate access to information about the laboratory facility, check the web homepage at "http://www.und.nodak.edu/dept/sem/electric.eng/mcl/."

111.1. Engine-Generator System: This system consists of a 5-hp gasoline engine which drives a single phase synchronous machine electric generator. The throttle of the engine is controlled by a five-phase stepper motor with a micro stepping controller. Hall effect power, voltage, current, and frequency transducers are used for feedback control and data acquisition. An adjustable electronic load is interfaced with the computer for automatic loading. Computer controlled excitation for the alternator's magnetic field is also implemented. The developed software provides engine speed control, alternator excitation and voltage control, electric load control, and full data acquisition.

111.2. Industrial Robot Arm: A five-degrees-of-freedom articulated industrial robot manipulator is reconfigured for interface with the computer. Full access to limit switches and joint actuators and encoders is provided. Digital Signal Processing (DSP) controllers are used to close the feedback loop on the joints. The original industrial controller is also available for optional use. The software provides full control of the joints and safe operation of the robot.

111.3. Adjustable Speed Drive: This system consists of a 5-hp induction motor driven by a variable speed field orientation power inverter and loaded by a programmable dynamometer. The computer provides full control of the inverter and the dynamometer. Power, torque, and speed are easily monitored.

111.4. DC Machine Servo System: A 3-hp de industrial motor is configured for position and speed control. A high resolution incremental dual-track shaft encoder is used for feedback sensing. The motor is loaded with a computer controlled magnetic clutch.

111.5. Accessory Equipment: The following pieces are available for integration with the basic work stations for special projects:

1. Three-dimensional force/torque transducer for use with the robot arm.

2. A platform supported by four force strain-gauges for sensing location of objects in the workspace of the robot arm.

3. Programmable Logic Controller (PLC) for implementing high performance or sequential control tasks. It is equipped with relay outputs, analog and digital I/Os, and incremental dual channel encoder feedback sensing.

4. DC motor actuator for throttle control of the engine.

5. Magnetic pickup speed sensor for use with the engine or the dc servo motor.

6. Harmonics analyzer for electric power quality monitoring.

7. Stand alone stepper motor for testing and characterization.

8. Voltage, current, and power transducers for use with any of the basic systems

9. Joy stick for use with the robot arm.

10. A speech recognition system for computer/user interface.

11. Variable frequency induction motor inverter.

12. MATLAB and LabView software.

13. Voltage, power, and current transducers. 


\section{Sample Projects}

Two classes of projects take place in the new laboratory; (1) senior design projects for three semester credits each, and (2) senior laboratory projects for one-third semester credit each. The scope and details of the project are determined according to its class. The following is a sample of these projects. It must be emphasized that in all these projects the student determines the scope of the project and the approach for conducting the work.

IV.1. Compliant control for the robot arm: Students interface the three-dimensional force/torque sensor with the computer and mount it on the gripper of the robot. The sensor measures the force vector and torque components with respect to the gripper coordinates. Using inverse kinematics for the robot arm the controller coordinates the joints of the robot to comply with the inserted force and torque on the gripper. This ultimate objective can be accomplished in a sequence of projects which may start by interfacing the sensor with the computer, run tests on the robot and identify its parameters, develop a mathematical model for the robot and evaluate it using MATLAB, study the inverse kinematics for the robot, and develop the software to implement the control scheme. Several control schemes can be tested. Computer simulation maybe used concurrently with the implementation of the controller for tuning and verification. It should be noted that the student can start with two degrees of freedom only to simplify the problem. The shoulder and the elbow joints can comply in a single plane to test the concept of compliant control. The work can then be extended to the three-dimensional workspace.

IV.2. Feedback via the strain-gauge platform: The strain-gauges provide the computer with the location of objects on the platform. The controller then directs the robot to perform a pick-and-place typical application. This project requires studying the inverse kinematics of the robot and simulating the robot arm to validate the developed model. The platform can also be used for higher performance applications like engraving where the robot follows a desired predetermined trajectory on the platform. The strain-gauges lead the robot in a real time control mode, This application requires using the dynamic model of IV. 1. above. The three dimensional sensor can be used concurrently with the platform to control the pressing force during the engraving process.

IV.3. Engine Modeling: In this project students may study the engine dynamics and its available models. They then conduct a sequence of tests to identify its parameters. A combination of static and dynamic tests under different loading conditions can be conducted. MATLAB is used to validate the model. Uncertainties, transport delay, and nonlinearities can be observed firsthand.

IV.4. Electric Generator Modeling: Standard test procedures maybe considered to identify the single phase alternator parameters. Limitations imposed by the controllability of the engine and its operating range require modifying the standard procedures which are based on ideal prime mover. Computer simulation validation is required in this project.

IV.5. Control Schemes: Numerous control schemes including PID, fuzzy logic, and sliding mode control can be implemented for speed control of the engine and dc servo motor, voltage control of the engine generator, and position control of the robot arm. Design procedures and computer simulation must be utilized in these projects.

IV.6. Electric Power Quality Evaluation: The harmonics analyzer is used to identify the harmonics created by the field orientation power inverter. Students study the theory of inverters and they use computer simulation to identify the source and type of harmonics. Computer simulation is also used to study the effect of harmonics on the performance of the motor. Different loading conditions are considered. A similar process is adopted to 
evaluate the variable frequency inverter. The two inverters are then compared and concluding remarks are made. The electric power produced by the engine-generator can also be evaluated for its harmonic content. The quality of electric power is determined for different control schemes. Moreover, nonlinear loads may be used with the engine-generator to examine potential operating problems.

IV.7. Speed Sensing for the Engine: Two possible speed feedback sensors maybe used to close the loop on the engine throttle. An electric output frequency transducer is used in the basic system. This transducer has an inherent delay which affects the performance of the controller. Students consider replacing the frequency transducer with a magnetic pick-up sensor to improve the performance of the controller. Computer simulation is used to determine the effect of delays on feedback loops. The minor loop on the throttle actuator can also be closed for position control versus the speed control mode. One must differentiate between speed control for the engine shaft and speed control for the throttle actuator shaft.

IV.8. Energy Saving: The adjustable speed drive system is used to simulate a typical daily, monthly, or annual motor load profile. The system runs in both modes of operation (variable speed and fixed speed) while monitoring energy consumption, Energy saving is then determined and fundamental conclusions are reached. Fan and pump loading conditions should be modeled properly by the student. Applications in Heating Ventilation and Air Conditioning (HVAC) can be investigated.

IV.9. Programmable Logic Controller (PLC) Applications: The PLC is used to control particular joints on the robot arm, close the loop on the engine, provide excitation control for the generator, or close the loop on the dc servo motor for position or speed control.

IV.1O. Motion Control Using Induction Motor: The induction motor is investigated as a high performance motion control actuator. The field orientation inverter makes the induction motor perform like a linear dc motor. Control for speed and position is applied. Students experiment with the system and characterize the invertermotor for their equivalent linear model.

IV.11. Analog Controllers: Several projects can be created by students to design controllers and use analog circuits to implement them, The motivation in these projects is to present students with options other than digital control and give them the opportunity to evaluate analog versus digital implementation.

\section{Educational Objectives and Challenges}

Each of the projects in the previous section presents an open-ended experimental activity to be performed by the student, Students develop their own investigative plans and determine the scope of their work. They are allowed to pick and choose from a list of ideas, mix them, or come up with their own. This environment encourages creativity and critical thinking. The student becomes an active learner and he/she assumes an ownership in the laboratory exercise. Interdisciplinary activities are noticed in many of the listed projects. The development of this new laboratory by itself provided several students with a significant design experience. Four students worked with the principal investigator on putting the laboratory together. Many options for configuring the systems were considered, interface circuits were built, integration of sensors and instrumentation took place, and new software was developed. Many safety issues were considered and the students were active participants in accounting for them in the design of the basic systems.

In addition to the challenge of designing this new facility and creating a safe experimental environment, operating the new laboratory presents several other challenges among which are the following: 
1. It is important to insure a meaningful engineering experience. Many projects can fall short of making use of previous knowledge and engineering skills in analytical work and computer applications.

2. The breadth of background and possible solutions presents the instructor of the laboratory with a time demanding activity. Reading and brain storming with the students are important.

3. Students must be permitted sufficient time to get acquainted with the equipment. The many user manuals and system components may create an intimidating environment that should be avoided. It is important for the student to realize that mastering every piece of equipment in the system is not the purpose of the laboratory. It is rather the problem solving skill and the specific focus of the project that is important.

4. Large classes with several sections may pose difficulty in scheduling equipment especially if some of the groups are making modifications in the configuration of the basic system.

5. Funds should be available to acquire additional accessory components as needed for new projects.

\section{Conclusions}

The new laboratory is running for the second time this semester (Spring '96). The first time, the laboratory was used as an integral part of a first control systems course. The students were required to do small two week projects. They were asked to identify problems and work closely with the instructor to accomplish their goal. The laboratory was successful and the students seemed to be able to grasp new implementation and modeling concepts better. This semester, students are completing five-week projects. They seem to be progressing well and able to meet the educational objectives of the new laboratory.

One of the major advantages of the new facility is its anticipated dynamic growth with time. Projects which require new accessory components will add to the laboratory inventory and provide more flexibility in identifying projects. We expect students to be better prepared for capstone design after they have completed this senior laboratory.

\section{Acknowledgment}

This work was partially funded by the National Science Foundation (NSF) through ILI grant \# DUE9351740. The School of Engineering and Mines at the University of North Dakota provided matching funds and physical space renovation.

\section{References}

1. James C. Conwell, George D. Catalano, and John E. Beard, "A Case Study in Creative Problem Solving in Engineering Design,” Journal of Engineering Education, October 1993, pp. 227-231.

2. David Cyganski, Denise Nicoletti, and John A. Orr, "A New Introductory Electrical Engineering Curriculum for The First-Year Student,” IEEE Trans. On Education, vol. 37, no, 2, May 1994, pp. 171-177.

3. Juris Vagners, "Some Perspectives on Teaching Engineering Design," The American Institute of Aeronautics and Astronautics, 1992. 
4. N.N. Bengiamin, "Undergraduate Open-Ended Laboratory Experiences,” ASEE Annual Conference Proceedings, 1995, pp. 2708-2715.

5. N. N. Bengiamin, “Open-Ended Cross-Disciplinary Motion Control and Energy Management Laboratory Experiences," Proceedings of the Automatic Control Conference, June 1995, pp. 1884-1888.

\section{Biography}

Dr. Nagy Bengiamin is a professor with the Electrical Engineering Department at the University of North Dakota. He is presently the chairman of the department. Dr. Bengiamin received a Ph.D. in Electrical Engineering from the University of Calgary in Alberta, Canada in 1979. His teaching and research interests are in control systems, robotics, and electric power distribution, He consulted for the electric power and manufacturing industries. Dr. Bengiamin is a senior member of IEEE and member of ASEE. 